\title{
References values for forced spirometry
}

\author{
J. Roca*, F. Burgos*, J. Sunyer+, M. Saez+, S. Chinn\#, J.M. Antó+, \\ R. Rodríguez-Roisin*, Ph.H. Quanjerł, D. Nowak§, P. Burney\#, \\ for the Group of the European Community Respiratory Health Survey
}

Reference values for forced spirometry. J. Roca, F. Burgos, J. Sunyer, M. Saez, S. Chinn, J.M. Antó, R. Rodríguez-Roisin, PhH. Quanjer, D. Nowak, P. Burney, for the Group of the European Community Respiratory Health Survey. @ERS Journals Ltd 1998.

ABSTRACT: The European Coal and Steel Community (ECSC) prediction equations exemplify a significant effort carried out approximately 15 yrs ago to provide uniform standards for lung function testing, but this set of equations has not been properly validated as yet. The present study evaluates the ECSC reference values and four other sets of prediction equations, using spirometric data collected in 12,900 nonasthmatic subjects (43\% lifetime nonsmokers and 36\% active smokers) aged 20-44 yrs from the European Community Respiratory Health Survey (ECRHS).

Standardized spirometric measurements were obtained using a common protocol in 34 centres in 14 countries. For each prediction equation, the prediction deviations (i.e. observed minus predicted value) for forced vital capacity (FVC) and forced expiratory volume in one second (FEV1) were examined for the whole study population and for each centre.

For the age range included, the errors about the ECSC equations showed the most prominent underestimation of both predicted FVC $(+355$ and $+360 \mathrm{~mL}$ on average in males and females, respectively) and predicted FEV1 $(+211$ and $+200 \mathrm{~mL}$, respectively) among the five studies examined. As expected, FVC and FEV1 in active smokers from the ECRHS were significantly lower than in lifetime nonsmokers (each p<0.01).

We conclude that the present European recommendations on lung function reference values should be reconsidered, but further data for nonsymptomatic subjects above the age of $44 \mathrm{yrs}$ are needed.

Eur Respir J 1998; 11: 1354-1362.
*Servei de Pneumologia i Al.lèrgia Respiratòria, Dept de Medicina, Hospital Clínic, Universitat de Barcelona, Spain. +Dept d'Epidemiologia, Institut d'Investigació Mèdica (IMIM), Universitat Autònoma de Barcelona, Spain. \#Dept of Public Health Medicine, UMDS, St Thomas' Campus, London, UK. :Physiology Dept, Leiden University, The Netherlands. \&Krankenhaus Grosshansdorf, Zentrum für Pneumologie und Thoraxchirurgie, and Institute of Occupational Medicine, University of Hamburg, Germany.

Correspondence: J. Roca, Servei de Pneumologia i Al.lèrgia Respiratòria, Hospital Clínic, Villarroel 170, Barcelona 08036, Spain, Fax: 34932275455

Keywords: Forced spirometry prediction equations

reference values

smoking effects

standardization

Received: May 261997

Accepted after revision February 271998
Selected sets of reference values for forced spirometry derived from nonsmoking, white subjects [1] show marked differences among studies [2-6] in both predicted forced vital capacity (FVC) (up to $640 \mathrm{~mL}$ ) and predicted forced expiratory volume during the first second (FEV1) (up to $310 \mathrm{~mL}$ ). The magnitude of the differences among reference values gives rise to potential concerns for the clinical assessment of ventilatory capacity. Moreover, it has been suggested recently in a preliminary study that the European Coal and Steel Community (ECSC) prediction equations $[2,7]$ significantly underestimate predicted FVC and predicted FEV1 $[8,9]$.

The main goal of the present study was to evaluate five sets of prediction equations for forced spirometry: the ECSC predicted values [2, 7] and those reported by four other authors $[3,4,10,11]$, using standardized spirometric measurements from 12,900 nonasthmatic subjects aged 20-44 yrs pertaining to the European Community Respiratory Health Survey (ECRHS). The four sets of prediction equations, (KNUDSON et al. [10], PAOLETTI et al. [4], CRAPO et al. [11], and RocA et al. [3]), examined in addition to the ECSC reference values, were selected in the present study among those included in [1] because they had followed current standards for forced spirometry $[2,12]$.

The ECRHS is a multicentre study of the variation in the prevalence, risk factors and management of asthma throughout the European Union and elsewhere [13], and includes standardized measurements of forced spirometry collected using a common protocol in 34 centres in 14 countries.

\section{Methods}

\section{Subjects}

The protocol for the ECRHS has been described elsewhere [13-15]. In brief, participating centres selected an area defined by pre-existing administrative boundaries, with a population of at least 150,000 individuals. Where possible, an up-to-date sampling frame was used to select randomly at least 1,500 males and 1,500 females, aged 20-44 yrs. In stage I, subjects were sent a questionnaire 
enquiring about respiratory symptoms and attacks of asthma over the last 12 months, current use of asthma medication and nasal allergies, including hay fever. A random sample of subjects was selected to take part in stage II. Those who had already responded to stage I were invited to answer a more detailed administered questionnaire, and to take part in blood tests, skin tests, assessment of lung function by spirometry and airway challenge with methacholine. The questionnaire collected information on health status, current smoking and smoking history.

Of 43 centres participating in stage II, data from 34 centres in 14 countries was included. Five centres had not fully checked and edited their data, and others supplied data after the deadline for this analysis, but the response to stage II varied from $12.2 \%$ (Montpellier, France) to $90.3 \%$ (Umeå, Sweden) of those selected. The overall response rate for stage II of the areas included in the present study was $48.1 \%$. Among the 16,689 subjects participating in stage II, 12,900 were included in the present analysis. Subjects who reported asthma-related symptoms were excluded. In the ECRHS, a subject with asthmarelated symptoms was defined as one who reported any of the following three conditions: 1) being woken up by an attack of shortness of breath at any time over the last 12 months; 2) having an attack of asthma during the last 12 months; and 3) currently taking any medicine for asthma (including inhalers, aerosols or tablets). Consequently, the present study did not exclude past or present smokers, or subjects with current or previous respiratory disease other than asthma or any condition that may affect ventilatory function.

\section{Spirometric measurements and quality control}

Standardization of forced spirometry is described in detail in the protocol [14]. In brief, baseline FVC and FEV1 were measured in all subjects who agreed to these tests. Subjects were permitted nine attempts to provide at least two technically acceptable manoeuvres. All of the techni-

Table 1. - Main characteristics of the studies on reference values for forced spirometry

\begin{tabular}{|c|c|c|c|c|c|}
\hline & \multicolumn{5}{|c|}{ Study sample } \\
\hline & $\overline{\mathrm{ECSC}}[2,7]$ & KNUDSON et al. [10] & PAOLETTI e $t$ al. [4] & CRAPO et al. [11] & RoCA et al. [3] \\
\hline & $\begin{array}{l}\text { Summary equations } \\
\text { obtained from } \\
\text { different studies as } \\
\text { reported in Ref. [2] }\end{array}$ & $\begin{array}{l}\text { Randomly selected } \\
\text { sample from the } \\
\text { general population } \\
\text { of the area }\end{array}$ & $\begin{array}{l}\text { Randomly selected } \\
\text { sample from the } \\
\text { general population } \\
\text { of the area }\end{array}$ & $\begin{array}{l}\text { Selected } \\
\text { volunteer* }\end{array}$ & $\begin{array}{l}\text { Selected } \\
\text { volunteers }\end{array}$ \\
\hline$\overline{\text { Country }}$ & - & Arizona (USA) & Italy & Utah (USA) & Spain \\
\hline Altitude & - & SL & SL & $1400 \mathrm{~m}$ & SL \\
\hline Age yrs & - & $\begin{array}{l}20-85 \text { (males) } \\
20-88 \text { (females) }\end{array}$ & $\begin{array}{l}\text { 29-64 (males) } \\
21-64 \text { (females) }\end{array}$ & $15-84$ & $20-70$ \\
\hline Smokers & - & No & No & No & No \\
\hline Males & - & 86 & 59 & 126 & 443 \\
\hline Females & - & 204 & 313 & 125 & 427 \\
\hline Body position & - & Sitting & Sitting & Sitting & Sitting \\
\hline Equipment & - & Pneumotachograph & $\begin{array}{l}\text { Fleisch No. } 3 \\
\text { pneumotach } \\
\text { HP47804 System }\end{array}$ & $\begin{array}{l}\text { Water-sealed } 13.5 \mathrm{~L} \\
\text { metal bell } \\
\text { spirometer }\end{array}$ & $\begin{array}{l}\text { Fleisch No. } 3 \\
\text { pneumotach } \\
\text { HP47804 HP Vertek } \\
\text { System }\end{array}$ \\
\hline \multicolumn{6}{|l|}{ Calculations } \\
\hline Beginning of test & - & Back-extrapolation & Back-extrapolation & Back-extrapolation & Back-extrapolation** \\
\hline End of test & - & Flow $<50 \mathrm{~mL} \cdot \mathrm{s}^{-1}$ & Flow $<15 \mathrm{~mL} \cdot \mathrm{s}^{-1}$ & Flow $<50 \mathrm{~mL} \cdot \mathrm{s}^{-1}$ & Flow $<15 \mathrm{~mL} \cdot \mathrm{s}^{-1}$ \\
\hline
\end{tabular}

European Coal and Steel Community (ECSC) (Ref. [2], Chap. 7, pp. 45-51) provides detailed information about the items indicated in the table. SL: sea level or close to sea level. *: members of the Church of Jesus Christ of Latter-Day Saints. **: modified forced expiratory volume in one second (FEV1) prediction equation [3].

Table 2. - Prediction equations examined in the present study

\begin{tabular}{|c|c|c|c|c|c|c|}
\hline & \multicolumn{3}{|c|}{ FVC L (males) } & \multicolumn{3}{|c|}{ FVC L (females) } \\
\hline & Equation & $\mathrm{r}^{2}$ & RSD & Equation & $\mathrm{r}^{2}$ & RSD \\
\hline$\overline{\mathrm{ECSC}}[7]$ & $0.0576 \mathrm{H}-0.0260 \mathrm{~A}-4.340$ & $\mathrm{NA}$ & 0.61 & $0.0443 \mathrm{H}-0.0260 \mathrm{~A}-2.890$ & $\mathrm{NA}$ & 0.43 \\
\hline KNuDson et al. [10] & $0.0844 \mathrm{H}-0.0298 \mathrm{~A}-8.782$ & 0.72 & 0.64 & $0.0444 \mathrm{H}-0.0169 \mathrm{~A}-3.195$ & 0.49 & 0.48 \\
\hline PAOLETTI et al. [4] & $0.0724 \mathrm{H}-0.0273 \mathrm{~A}-6.382$ & 0.48 & 0.58 & $0.0412 \mathrm{H}-0.0154 \mathrm{~A}-2.329$ & 0.38 & 0.39 \\
\hline CRAPO et al. [11] & $0.0600 \mathrm{H}-0.0214 \mathrm{~A}-4.650$ & 0.53 & 0.64 & $0.0491 \mathrm{H}-0.0216 \mathrm{~A}-3.590$ & 0.74 & 0.39 \\
\hline \multirow[t]{3}{*}{ Roca et al. $\lceil 3]$} & $0.0678 \mathrm{H}-0.0147 \mathrm{~A}-6.055$ & 0.52 & 0.53 & $0.0454 \mathrm{H}-0.0211 \mathrm{~A}-2.825$ & 0.56 & 0.40 \\
\hline & \multicolumn{3}{|c|}{ FEV1 L (males) } & \multicolumn{3}{|c|}{ FEV1 L (females) } \\
\hline & Equation & $\mathrm{r}^{2}$ & RSD & Equation & $\mathrm{r}^{2}$ & RSD \\
\hline ECCS [7] & $0.0430 \mathrm{H}-0.0290 \mathrm{~A}-2.490$ & $\mathrm{NA}$ & 0.51 & $0.0395 \mathrm{H}-0.025 \mathrm{~A}-2.600$ & $\mathrm{NA}$ & 0.38 \\
\hline KNuDson et al. $[10]$ & $0.0665 \mathrm{H}-0.0292 \mathrm{~A}-6.515$ & 0.74 & 0.52 & $0.0665 \mathrm{H}-0.0292 \mathrm{~A}-6.515$ & 0.74 & 0.52 \\
\hline PAOLETTI et al. [4] & $0.0494 \mathrm{H}-0.0275 \mathrm{~A}-3.576$ & 0.35 & 0.48 & $0.0243 \mathrm{H}-0.0196 \mathrm{~A}-0.282$ & 0.48 & 0.29 \\
\hline CRAPO et al. [11] & $0.0414 \mathrm{H}-0.0244 \mathrm{~A}-2.190$ & 0.64 & 0.49 & $0.0342 \mathrm{H}-0.0255 \mathrm{~A}-1.578$ & 0.79 & 0.33 \\
\hline Roca et al. [3] & $0.0514 \mathrm{H}-0.0216 \mathrm{~A}-3.955$ & 0.56 & 0.45 & $0.0326 \mathrm{H}-0.0253 \mathrm{~A}-1.286$ & 0.67 & 0.32 \\
\hline
\end{tabular}

ECSC: European Coal and Steel Community. FVC: forced vital capacity; FEV1: forced expiratory volume in one second; H: height $(\mathrm{cm})$; A: age (yrs); $\mathrm{r}^{2}$ : squared multiple correlation coefficient; RSD: residual standard deviation; NA: not available. 
cians involved in the study, irrespective of their previous background, received identical training. At the start of the ECRHS, a quality-control visit to each laboratory was carried out, either by the personnel of the Coordinating Centre (London) or by two investigators of the ECRHS in the corresponding country to examine all of the procedures involved in the protocol. They specifically checked the volume signal of the equipment using a $3 \mathrm{~L}$ calibrated syringe and examined the equipment for leaks. The equipment used in each centre is reported in the Appendix. During the study, technicians were instructed to verify the volume signal of the equipment on a daily basis using calibrated syringes ( 2 or $3 \mathrm{~L}$ ).

\section{Reference equations}

The main characteristics of the five sets of reference equations examined in this study are shown in tables 1 and $2[3,4,10,11]$. The ECSC equations [2, 7] were derived from data from different studies carried out before the 1980s using different methods and from differing populations, as reported in [2]. The remaining four studies were derived following modern standards $[2,12]$ and they were reported throughout the 1980s. Prediction equations for FEV1 by Roca et al. [3] in the present study were corrected to back-extrapolation following the calculations reported in [3].

\section{Data analysis}

Predicted values for FVC and FEV1 were computed for each of the equations. One-way analysis of variance (ANOVA) was carried out, where the prediction deviations (i.e. observed minus predicted value) were the dependent variables and centres the factor variable. The confidence interval of the mean prediction deviations was calculated for each centre using the standard deviation observed in that centre rather than that of the whole population. In a second step, a two-way ANOVA, including centres and smoking, was carried out to control for the effects of smoking on the prediction deviations by centres. Modification of the effects of smoking by age was assessed in the same model with the interaction of age and smoking. The variable smoking was analysed as: active 1 smokers, exsmokers and lifetime nonsmokers. A p-value of $<0.05$ was considered statistically significant.

Mean values of prediction deviations for each of the five sets of prediction equations were examined and compared with the corresponding standardized prediction deviations (i.e. mean prediction deviation/RSD). RSD is the residual standard deviation of the corresponding prediction equation.

\section{Results}

Anthropometric and lung function data of the 12,900 subjects included in the present study are set out in table 3 . The mean and $95 \%$ confidence interval $(95 \% \mathrm{CI})$ of the prediction deviations in each centre for each of the five sets of reference equations are illustrated in figures 1-4
Table 3. - Anthropometric and lung function data

\begin{tabular}{lcc}
\hline & Males & Females \\
\hline Subjects n & 6479 & 6419 \\
Active smokers \% & 39 & 33 \\
Exsmokers \% & 21 & 21 \\
Lifetime nonsmokers \% & 40 & 46 \\
Age yrs & $33 \pm 7.0$ & $33 \pm 7.0$ \\
Height cm & $177 \pm 7$ & $164 \pm 6$ \\
Weight kg & $78 \pm 12$ & $63 \pm 11$ \\
FVC L & $5.37 \pm 0.83$ & $3.87 \pm 0.58$ \\
FEV 1 L & $4.39 \pm 0.69$ & $3.25 \pm 0.50$ \\
FEV 1/FVC \% & $82 \pm 7$ & $84 \pm 6$ \\
PEFR L.s ${ }^{-1}$ & $9.96 \pm 2.04$ & $6.86 \pm 1.37$ \\
\hline
\end{tabular}

FVC: forced vital capacity; FEV1: forced expiratory volume in one second; PEFR: peak expiratory flow rate. Results are expressed as mean $\pm \mathrm{SD}$.

for FVC (males), FVC (females), FEV1 (males), and FEV1 (females), respectively. Results for each centre and country are reported in the Appendix. In figures 1-4, the horizontal dashed lines indicate a lack of difference between observed and predicted values. Accordingly, those centres whose $95 \%$ CI did not intercept with the corresponding horizontal dashed line showed a statistically significant difference between observed and predicted values.

The ECSC equations underpredicted FVC and FEV1 in both males and females. The mean of the prediction deviations for FVC in all the centres was $+355 \mathrm{~mL}$ in males and $+360 \mathrm{~mL}$ in females. Only one centre (Montpellier, France) in males and two centres (Albacete, Spain and Bergen, Norway) in females displayed significantly lower observed than predicted FVC values. The mean of the prediction deviations for FEV1 was $+211 \mathrm{~mL}$ in males and $+200 \mathrm{~mL}$ in females. Similarly, only two centres (Albacete, Spain and Bergen, Norway) showed negative prediction deviations in males and only two centres (Bordeaux, France and Bergen, Norway) in females.

Predicted values by KNUDSON et al. [10] in females displayed a picture very similar to that seen in the ECSC equations. The mean of the prediction deviations was +340 $\mathrm{mL}$ for FVC and +250 mL for FEV1. In males, KNuDson et al. [10] also underpredicted FVC and FEV1, but the magnitude of the prediction deviations $(+170 \mathrm{~mL}$ and +70 $\mathrm{mL}$, respectively) was smaller than in females. PAOLETTI $e t$ al. [4] overestimated FVC particularly in ma-les (21 centres, $62 \%$, showed significantly lower observed than predicted values and only one centre displayed a positive mean of prediction deviations in this variable). The mean of the prediction deviations for FVC in all of the centres was $-190 \mathrm{~mL}$ in males and $-50 \mathrm{~mL}$ in females. In contrast, PAoletTI et al. [4] underpredicted FEV1 in both sexes. The mean of the prediction deviations was $+112 \mathrm{~mL}$ and +200 $\mathrm{mL}$, respectively. Up to 24 centres $(71 \%)$ in males and 30 centres $(88 \%)$ in females showed higher observed than predicted FEV1. Accordingly, predicted values for the FEV1/FVC ratio by these authors [4], 77\% for males and $78 \%$ for females, were significantly lower than the actual FEV1/FVC ratio from the ECRHS, as indicated in table 3.

Observed and predicted FEV 1 were closer both in CRAPO et al. [11] (mean of the prediction errors: $+45 \mathrm{~mL}$ in males and $+60 \mathrm{~mL}$ in females) and in Roca et al. [3] $(-57 \mathrm{~mL}$ in males and $+30 \mathrm{~mL}$ in females) than in the other sets of reference equations analysed $[4,10,11]$. However, 

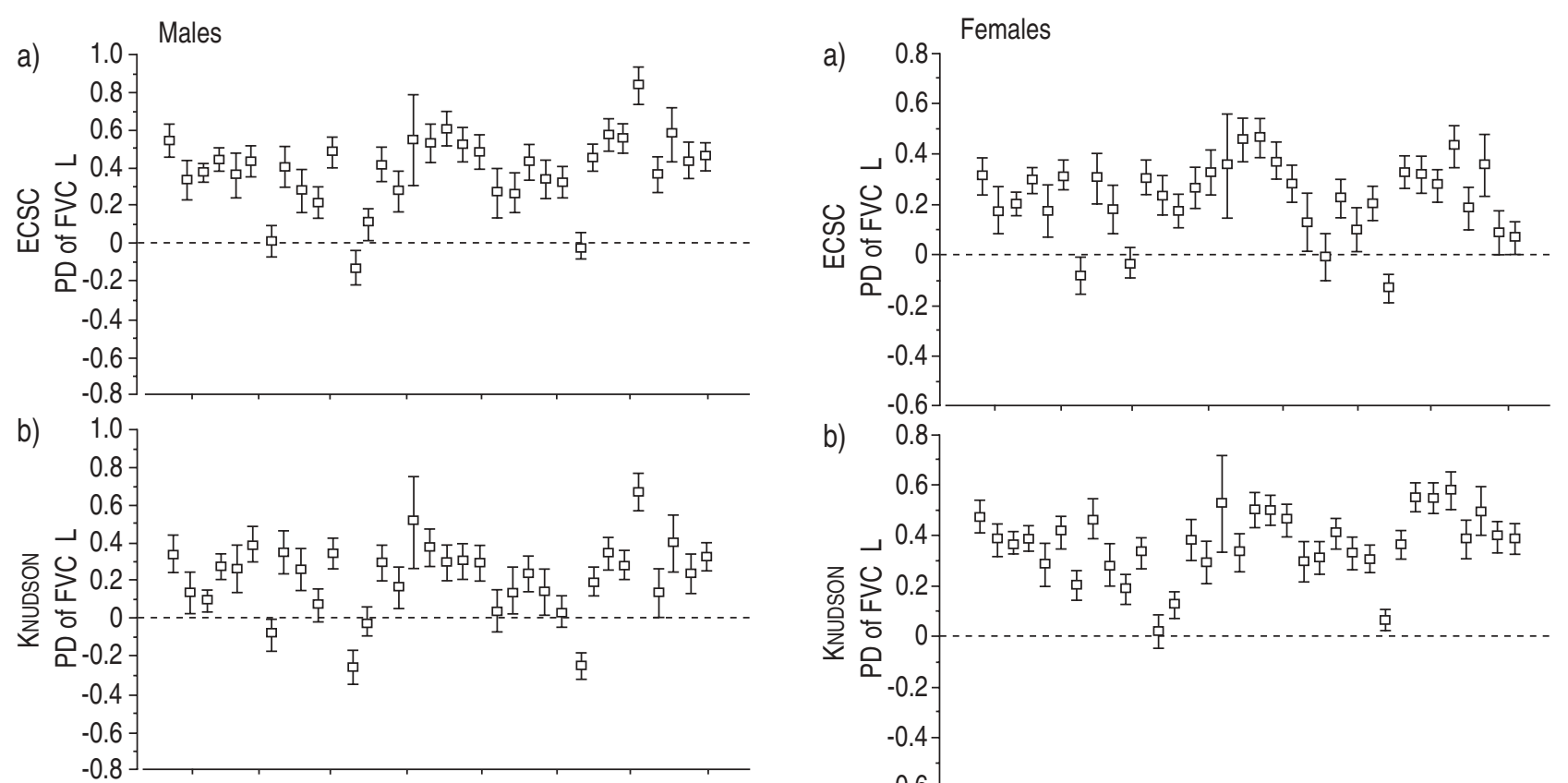

b)
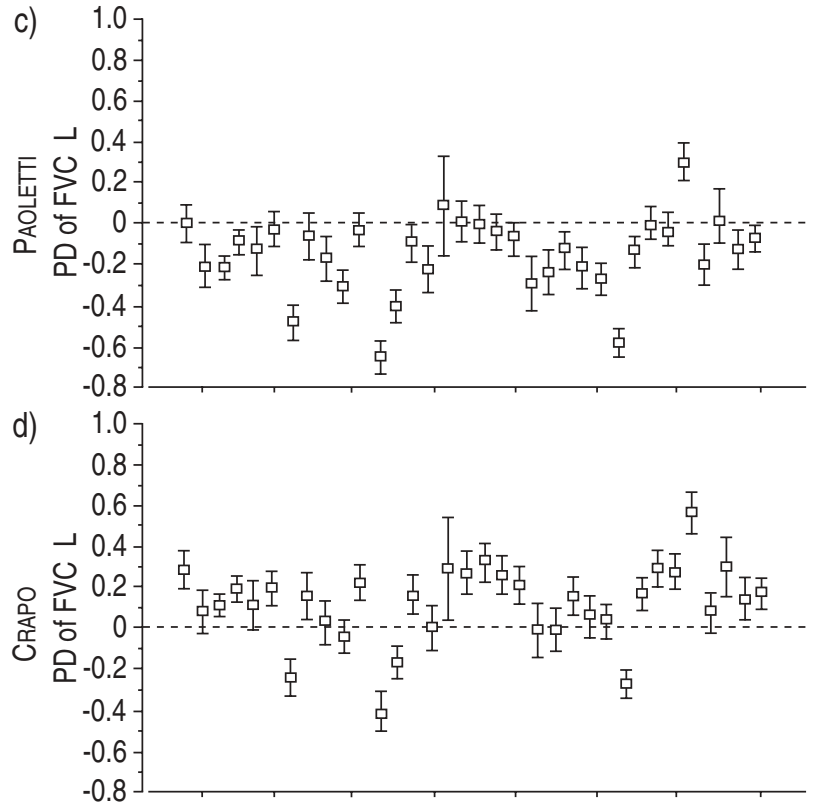

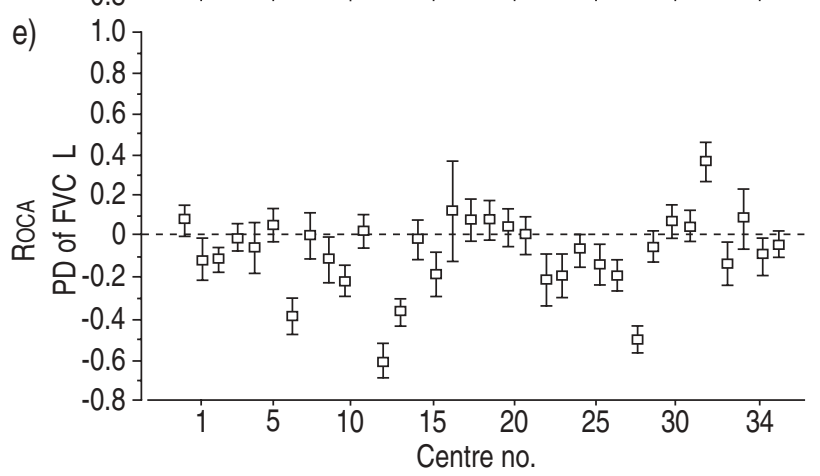

Fig. 1. - The symbols correspond to mean $\pm 95 \%$ confidence intervals of the prediction deviations (PD) (observed-predicted value) in each centre for forced vital capacity (FVC) in males. From the studies of a) European Coal and Steel Community (ECSC) [2,7]; b) KNUDSON et al. [10]; c) PAOLETTI et al. [4]; d) CRAPO et al. [11]; and e) Roca et al. [3]. Identification of centres and countries and numerical data for each centre following the same order are given in the Appendix.
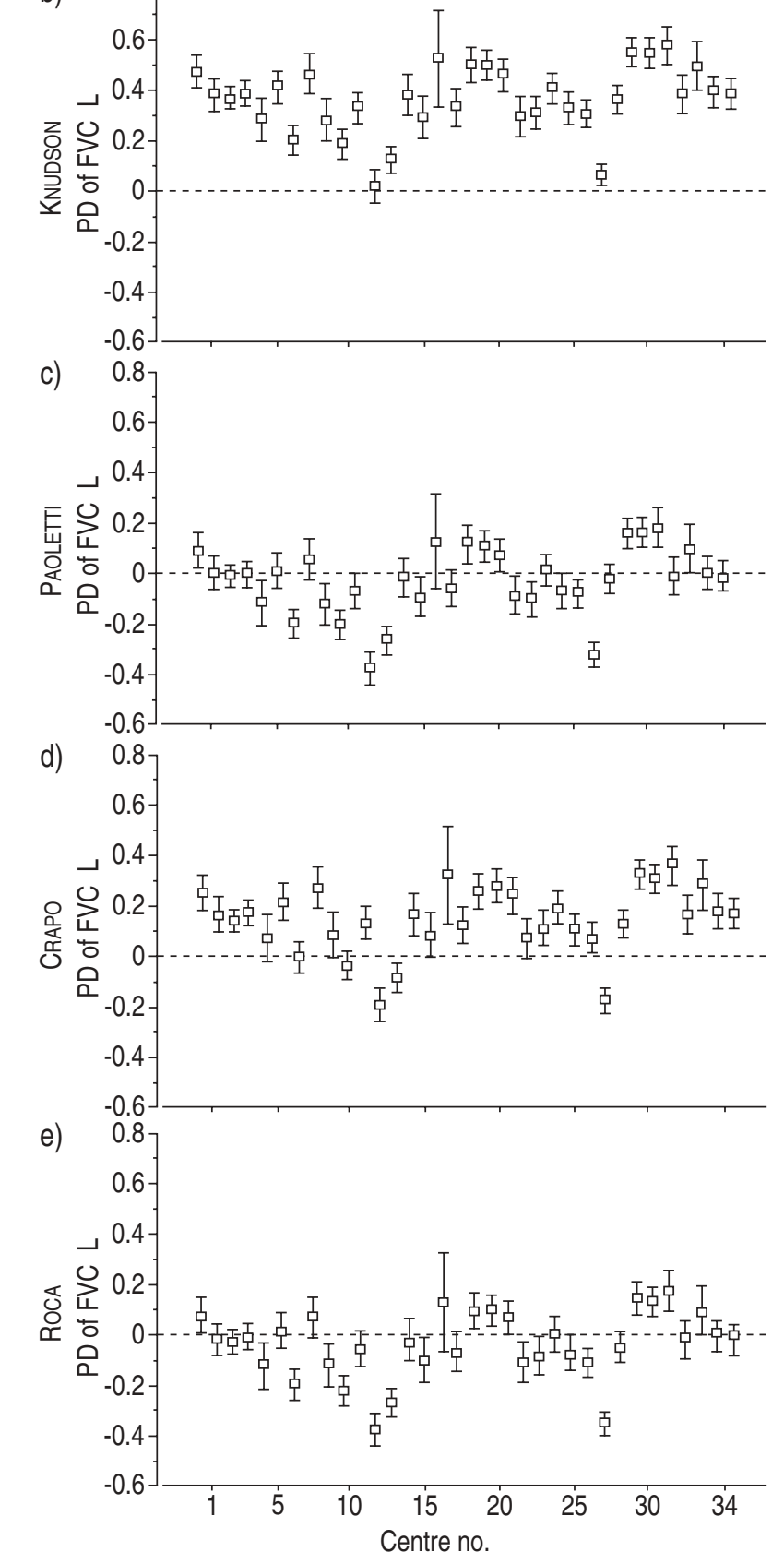

Fig. 2. - Mean $\pm 95 \%$ confidence intervals of the prediction deviations (PD) in each centre for forced vital capacity (FVC) in females. From the studies of a) European Coal and Steel Community (ECSC) [2, 7]; b) KNUDSON et al. [10]; c) PAOLETTI et al. [4]; d) CRAPO et al. [11]; and e) RocA et al. [3]. See legend to figure 1 for further information. 

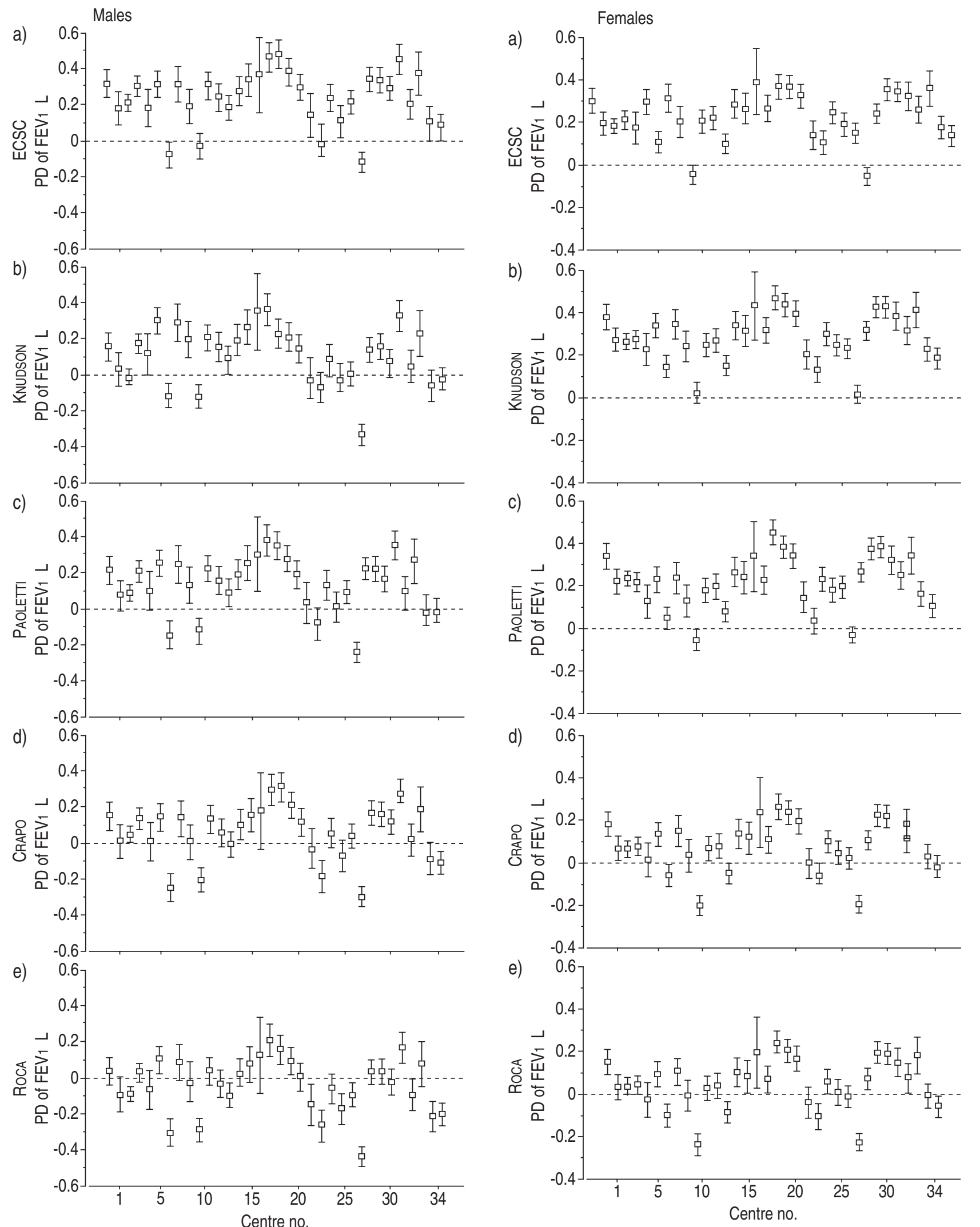

Fig. 3. - Mean $\pm 95 \%$ confidence intervals of the prediction deviations (PD) in each centre for the forced expiratory volume in one second (FEV1) in males. From the studies of a) European Coal and Steel Community (ECSC) [2, 7]; b) KNUDSON et al. [10]; c) PAOLETTI et al. [4]; d) CRAPO et al. [11]; and e) Roca et al. [3]. See legend to figure 1 for further information.

Fig. 4. - Mean $+95 \%$ confidence intervals of the prediction deviations (PD) in each centre for the forced expiratory volume in one second (FEV 1 ) in females. From the studies of a) European Coal and Steel Community (ECSC) $[2,7]$; b) KNUdSON et al. [10]; c) PAOletTI et al. [4]; d) CRAPO et al. [11]; and e) RocA et al. [3]. See legend to figure 1 for further information. 
Table 4. - Prediction deviations in active smokers and lifetime nonsmokers

\begin{tabular}{|c|c|c|c|c|}
\hline & \multicolumn{2}{|c|}{ FVC $\mathrm{mL}$} & \multicolumn{2}{|c|}{ FEV1 $\mathrm{mL}$} \\
\hline & $\begin{array}{l}\text { Active smokers } \\
(2525 \mathrm{M} / 2120 \mathrm{~F})\end{array}$ & $\begin{array}{l}\text { Lifetime nonsmokers } \\
(2590 \mathrm{M} / 2956 \mathrm{~F})\end{array}$ & Active smokers & Lifetime nonsmokers \\
\hline \multicolumn{5}{|c|}{ ECSC [7] } \\
\hline M & $284 \pm 636$ & $376 \pm 636$ & $123 \pm 540$ & $260 \pm 533$ \\
\hline $\mathrm{F}$ & $315 \pm 480$ & $341 \pm 475$ & $139 \pm 406$ & $204 \pm 388$ \\
\hline \multicolumn{5}{|c|}{ KNubson et al. [10] } \\
\hline M & $113 \pm 647$ & $159 \pm 645$ & $0 \pm 556$ & $101 \pm 543$ \\
\hline $\mathrm{F}$ & $309 \pm 471$ & $336 \pm 464$ & $201 \pm 406$ & $265 \pm 387$ \\
\hline \multicolumn{5}{|c|}{ Paoletti et al. [4] } \\
\hline M & $-248 \pm 634$ & $-180 \pm 632$ & $29 \pm 540$ & $158 \pm 529$ \\
\hline $\mathrm{F}$ & $-79 \pm 472$ & $-53 \pm 465$ & $143 \pm 414$ & $204 \pm 397$ \\
\hline \multicolumn{5}{|c|}{ CRAPO et al. [11] } \\
\hline M & $18 \pm 634$ & $114 \pm 630$ & $-46 \pm 543$ & $101 \pm 533$ \\
\hline $\mathrm{F}$ & $84 \pm 474$ & $112 \pm 467$ & $4 \pm 406$ & $67 \pm 389$ \\
\hline \multicolumn{5}{|c|}{ Roca et al. [3] } \\
\hline M & $-177 \pm 634$ & $-81 \pm 623$ & $-141 \pm 544$ & $4 \pm 528$ \\
\hline $\mathrm{F}$ & $-89 \pm 474$ & $-62 \pm 467$ & $-32 \pm 407$ & $31 \pm 390$ \\
\hline
\end{tabular}

European Coal and Steel Community. FVC: forced vital capacity; FEV1: forced expiratory volume in one second; M: males; F: females. Results are expressed as mean \pm SD. Exsmokers (1,360 males and 1,349 females) are not included in the table.

CRAPO et al. [11] moderately underpredicted FVC (20 centres, $59 \%$, in males and 24 centres, $71 \%$, in females showed significant positive prediction errors). The mean of the prediction deviations was $+88 \mathrm{~mL}$ in males and $+120 \mathrm{~mL}$ in females. In contrast, ROCA et al. [3] slightly overpredicted FVC (15 centres, 44\%, in males and 13 centres, $38 \%$, in females showed significant negative prediction errors). The mean of the prediction deviations being -120 $\mathrm{mL}$ in males and $-60 \mathrm{~mL}$ in females.

The geographical distribution of the prediction deviations between the different centres and countries (figs. 14 and Appendix) did not show any particular pattern. Moreover, the overall dispersion (table 4) of the prediction deviation was similar for the five sets of equations examined. Analysis of the standardized prediction deviations did not change the overall picture given in the present study.

Prediction deviations in active smokers and lifetime nonsmokers are shown in table 4 . The distribution of prediction deviations by centres depicted in figs. 1-4 was preserved after adjusting for the effects of tobacco. It is worth noting that the magnitude of the prediction deviations in lifetime nonsmokers by RoCA et al. [3] was negligible for FEV1 (100\% and $101 \%$ predicted in males and females, respectively), and only slightly higher for FVC ( $99 \%$ and $98 \%$ pred, respectively).

Active smokers showed a significantly lower FVC and FEV1 than lifetime nonsmokers (each $\mathrm{p}<0.01$ ). As expected, the deleterious effect of tobacco smoking on lung function was more evident in males than in females and, in both sexes, it was more marked in FEV1 than in FVC. The effects of smoking on lung function varied with age, but because of the limited age range examined in the present study, the interactions between smoking and age were not analysed further.

\section{Discussion}

The present study indicates that FVC and FEV1 measured in 12,900 subjects from the ECRHS in 34 centres in 14 countries were markedly higher than the predicted values estimated by both the ECSC equations [7] and KNUdSon et al. [10], (figs. 1-4), in the age interval examined. Predicted values by PAOLETTI et al. [4] showed a moderate overestimation of FVC together with an underestimation of FEV1. Predicted values by CRAPO et al. [11] and Roca et al. [3] were the closest among those examined in the present study and both groups showed a reasonable agreement with the forced spirometric measurements carried out in the ECRHS. Moreover, from the results of Pistelli et al. [16] it can be presumed that the differences in predicted FVC between CRAPO et al. [11] and Roca et al. [3] could be reduced further (by $70 \mathrm{~mL}$ on average) if the FVC equations by CRAPO et al. [11] were corrected following the current end-of-test recommendations [7, 17]. The confirmation of a significant deleterious effect of active tobacco smoking on lung function in these relatively young subjects (tables 3 and 4 ) is the third piece of information provided by the present study.

The characteristics of the age interval analysed in the present study (young subjects from 20-44 yrs) preclude the use of lung function measurements from the ECRHS to generate new prediction equations for forced spirometry and may restrict the extrapolations based on ageadjusted analyses. The lack of information above the age of 44 yrs does not allow one to test for linearity of the decline in lung function with age, as it has been suggested by different studies $[1,18,19]$.

Discrepancies observed among the five sets of prediction equations $[2-4,10,11]$ examined in the present study can be explained by various methodological factors influencing spirometric measurements [1, 18]. Among them, technical factors (equipment, technicians, etc.) are more likely to play a principal role. The contribution of a cohort effect, however, cannot be excluded since the largest differences were observed in the earlier studies $[2,7,10]$. By contrast, potential ethnic differences between northern and southern European countries and the different methods used to select the reference sample (table 2) do not seem to be key factors in explaining the discrepancies among sets of prediction equations. A detailed review of the factors explaining why ECSC $[2,7]$ equations and KNUDSON 
Appendix 1. - Characteristics of the study population (males and females) by city and country

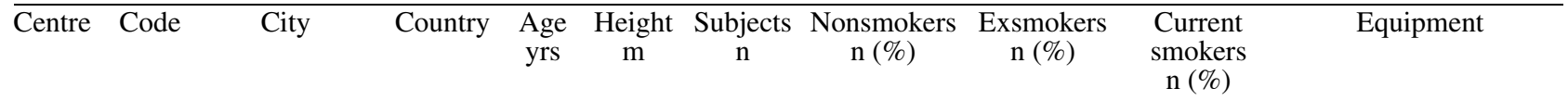

\begin{tabular}{|c|c|c|c|c|c|c|c|c|c|c|c|c|c|}
\hline \multicolumn{14}{|c|}{$\overline{\text { Males }}$} \\
\hline 1 & 10 & Antwerp-South & $\mathrm{B}$ & 32 & 1.79 & 181 & 88 & (49) & 34 & (19) & 59 & $(32)$ & Sensor Medics 2130 \\
\hline 2 & 12 & Antwerp-City & & 32 & 1.78 & 127 & 38 & (30) & 26 & (20) & 63 & $(50)$ & Sensor Medics 2130 \\
\hline 3 & 31 & Hamburg & $\mathrm{D}$ & 32 & 1.81 & 505 & 152 & (30) & 127 & (25) & 226 & (45) & Jaeger Pneumolab \\
\hline 4 & 33 & Erfurt & & 32 & 1.77 & 351 & 109 & (31) & 72 & (21) & 170 & (48) & Jaeger Pneumolab \\
\hline 5 & 50 & Barcelona & $\mathrm{E}$ & 32 & 1.74 & 98 & 30 & (31) & 20 & (20) & 48 & (49) & Biomedin \\
\hline 6 & 51 & Galdakao & & 31 & 1.72 & 203 & 60 & (30) & 27 & (13) & 116 & (57) & Biomedin \\
\hline 7 & 53 & Albacete & & 30 & 1.73 & 182 & 45 & (25) & 26 & (14) & 111 & (61) & Biomedin \\
\hline 8 & 54 & Oviedo & & 33 & 1.72 & 115 & 28 & (24) & 12 & (11) & 75 & (65) & Biomedin \\
\hline 9 & 55 & Huelva & & 32 & 1.71 & 113 & 35 & (31) & 10 & (9) & 68 & (60) & Biomedin \\
\hline 10 & 60 & Bordeaux & $\mathrm{F}$ & 31 & 1.76 & 227 & 83 & (36) & 52 & (23) & 92 & (41) & Vitalograph \\
\hline 11 & 61 & Grenoble & & 34 & 1.76 & 229 & 88 & (38) & 55 & (24) & 86 & (38) & Biomedin \\
\hline 12 & 62 & Montpellier & & 35 & 1.75 & 190 & 84 & (44) & 45 & (24) & 61 & (32) & Biomedin \\
\hline 13 & 64 & Paris & & 35 & 1.76 & 261 & 87 & (33) & 72 & (28) & 102 & (39) & Biomedin \\
\hline 14 & 70 & Dublin & IR & 32 & 1.75 & 146 & 60 & (42) & 27 & (18) & 59 & (40) & Biomedin \\
\hline 15 & 80 & Pavia & I & 34 & 1.75 & 125 & 42 & (34) & 16 & (13) & 67 & (53) & Biomedin \\
\hline 16 & 81 & Turin & & 33 & 1.72 & 95 & 49 & $(52)$ & 20 & (20) & 26 & $(28)$ & Biomedin \\
\hline 17 & 83 & Verona & & 32 & 1.76 & 147 & 54 & (36) & 36 & (25) & 57 & (39) & Biomedin \\
\hline 18 & 90 & Groningen & NL & 34 & 1.82 & 171 & 57 & (33) & 24 & (14) & 90 & (53) & Morgan Spirograph DS12 \\
\hline 19 & 91 & Bergen-op-Zoom & & 33 & 1.79 & 189 & 72 & $(38)$ & 39 & (21) & 78 & (41) & Morgan Spirograph DS12 \\
\hline 20 & 92 & Geleen & & 33 & 1.78 & 178 & 68 & (38) & 47 & (26) & 63 & (36) & Morgan Spirograph DS12 \\
\hline 21 & 110 & Cambridge & UK & 33 & 1.78 & 79 & 51 & (64) & 15 & (19) & 13 & $(17)$ & Biomedin \\
\hline 22 & 111 & Cardiff & & 34 & 1.74 & 136 & 60 & (44) & 26 & (19) & 50 & $(37)$ & Biomedin \\
\hline 23 & 113 & Ipswich & & 34 & 1.78 & 164 & 76 & (46) & 39 & (24) & 49 & (30) & Biomedin \\
\hline 24 & 115 & Norwich & & 33 & 1.77 & 148 & 65 & (44) & 43 & (29) & 40 & $(27)$ & Biomedin \\
\hline 25 & 130 & Reykjavik & $\mathrm{IC}$ & 33 & 1.81 & 246 & 79 & (32) & 61 & (25) & 106 & (43) & Sensor Medics 2450 \\
\hline 26 & 140 & Bergen & $\mathrm{N}$ & 33 & 1.81 & 355 & 153 & (43) & 48 & (14) & 154 & (43) & Sensor Medics Pne 12050 \\
\hline 27 & 150 & Göteborg & $\mathrm{S}$ & 33 & 1.80 & 256 & 120 & (47) & 49 & (19) & 87 & (34) & Sensor Medics 922 \\
\hline 28 & 151 & Umeå & & 33 & 1.79 & 214 & 111 & $(52)$ & 60 & (28) & 43 & $(20)$ & Sensor Medics 922 \\
\hline 29 & 152 & Uppsala & & 32 & 1.81 & 245 & 130 & (53) & 55 & (22) & 60 & $(25)$ & Sensor Medics 922 \\
\hline 30 & 180 & Wellington & NZ & 34 & 1.77 & 161 & 91 & $(56)$ & 32 & (20) & 38 & $(24)$ & Sensor Medics 2130 \\
\hline 31 & 182 & Christchurch & & 33 & 1.78 & 153 & 84 & $(55)$ & 43 & (28) & 26 & $(17)$ & Ohio 840 \\
\hline 32 & 183 & Hawkes-Bay & & 34 & 1.77 & 78 & 41 & (53) & 20 & (26) & 17 & (21) & Sensor Medics S4049 \\
\hline 33 & 191 & Portland & USA & 35 & 1.79 & 148 & 85 & (58) & 29 & (19) & 34 & $(23)$ & Spirotech S500 \\
\hline 34 & 220 & Melbourne & AUS & 34 & 1.76 & 259 & 127 & (49) & 57 & (22) & 75 & (29) & Hewlett Packard \\
\hline \multicolumn{14}{|c|}{ Females } \\
\hline 1 & 10 & Antwerp-South & $\mathrm{B}$ & 33 & 1.66 & 165 & 72 & (44) & 53 & $(32)$ & 40 & $(24)$ & Sensor Medics 2130 \\
\hline 2 & 12 & Antwerp-City & & 32 & 1.65 & 171 & 70 & (41) & 40 & (23) & 61 & (36) & Sensor Medics 2130 \\
\hline 3 & 31 & Hamburg & $\mathrm{D}$ & 33 & 1.68 & 440 & 159 & (36) & 101 & (23) & 180 & (41) & Jaeger Pneumolab \\
\hline 4 & 33 & Erfurt & & 33 & 1.64 & 308 & 136 & (44) & 65 & (21) & 107 & $(35)$ & Jaeger Pneumolab \\
\hline 5 & 50 & Barcelona & $\mathrm{E}$ & 32 & 1.60 & 97 & 33 & (34) & 20 & (21) & 44 & $(45)$ & Biomedin \\
\hline 6 & 51 & Galdakao & & 31 & 1.59 & 167 & 67 & (40) & 25 & (15) & 75 & $(45)$ & Biomedin \\
\hline 7 & 53 & Albacete & & 32 & 1.60 & 210 & 91 & (44) & 25 & (12) & 94 & (44) & Biomedin \\
\hline 8 & 54 & Oviedo & & 32 & 1.59 & 114 & 43 & (38) & 12 & (10) & 59 & $(52)$ & Biomedin \\
\hline $\begin{array}{l}0 \\
9\end{array}$ & 55 & Huelva & & 32 & 1.59 & 105 & 45 & (43) & 11 & (10) & 49 & (47) & Biomedin \\
\hline 10 & 60 & Bordeaux & $\mathrm{F}$ & 31 & 1.63 & 216 & 79 & (37) & 44 & (20) & 94 & (43) & Vitalograph \\
\hline 11 & 61 & Grenoble & & 35 & 1.63 & 194 & 90 & (48) & 58 & (30) & 42 & (22) & Biomedin \\
\hline 12 & 62 & Montpellier & & 34 & 1.63 & 199 & 102 & (51) & 46 & (23) & 51 & (26) & Biomedin \\
\hline 13 & 64 & Paris & & 34 & 1.64 & 286 & 120 & (42) & 72 & (25) & 94 & (33) & Biomedin \\
\hline 14 & 70 & Dublin & IR & 32 & 1.63 & 119 & 50 & (42) & 17 & (14) & 52 & (44) & Biomedin \\
\hline 15 & 80 & Pavia & I & 34 & 1.62 & 110 & 54 & (49) & 21 & (19) & 35 & (32) & Biomedin \\
\hline 16 & 81 & Turin & & 32 & 1.61 & 92 & 48 & (53) & 13 & (14) & 31 & (33) & Biomedin \\
\hline 17 & 83 & Verona & & 32 & 1.61 & 152 & 81 & (53) & 27 & (18) & 44 & (29) & Biomedin \\
\hline 18 & 90 & Groningen & NL & 33 & 1.69 & 170 & 75 & (44) & 30 & (17) & 65 & (39) & Morgan Spirograph DS12 \\
\hline 19 & 91 & Bergen-op-Zoom & & 33 & 1.65 & 207 & 74 & $(35)$ & 61 & (30) & 72 & $(35)$ & Morgan Spirograph DS12 \\
\hline 20 & 92 & Geleen & & 34 & 1.65 & 169 & 64 & (38) & 36 & $(21)$ & 69 & (41) & Morgan Spirograph DS12 \\
\hline 21 & 110 & Cambridge & UK & 33 & 1.65 & 112 & 66 & $(59)$ & 18 & $(16)$ & 28 & $(25)$ & Biomedin \\
\hline 22 & 111 & Cardiff & & 34 & 1.61 & 177 & 98 & (57) & 25 & (14) & 51 & (29) & Biomedin \\
\hline 23 & 113 & Ipswich & & 32 & 1.63 & 184 & 110 & (60) & 30 & (16) & 44 & $(24)$ & Biomedin \\
\hline 24 & 115 & Norwich & & 33 & 1.64 & 183 & 109 & (59) & 39 & (22) & 34 & (19) & Biomedin \\
\hline 25 & 130 & Reykjavik & $\mathrm{IC}$ & 32 & 1.67 & 245 & 103 & (42) & 53 & $(22)$ & 89 & (36) & Sensor Medics 2450 \\
\hline 26 & 140 & Bergen & $\mathrm{N}$ & 32 & 1.66 & 351 & 138 & (39) & 64 & (18) & 149 & (43) & Sensor Medics Pne 12050 \\
\hline 27 & 150 & Göteborg & $\mathrm{S}$ & 32 & 1.66 & 275 & 108 & (39) & 63 & $(23)$ & 104 & $(38)$ & Sensor Medics 922 \\
\hline 28 & 151 & Umeå & & 33 & 1.66 & 215 & 108 & $(50)$ & 40 & (19) & 67 & $(31)$ & Sensor Medics 922 \\
\hline 29 & 152 & Uppsala & & 33 & 1.66 & 235 & 117 & $(50)$ & 53 & (23) & 63 & $(27)$ & Sensor Medics 922 \\
\hline 30 & 180 & Wellington & NZ & 33 & 1.64 & 127 & 70 & (56) & 39 & (30) & 18 & (14) & Sensor Medics 2130 \\
\hline 31 & 182 & Christchurch & & 33 & 1.64 & 141 & 78 & $(54)$ & 29 & (20) & 36 & (26) & Ohio 840 \\
\hline 32 & 183 & Hawkes-Bay & & 33 & 1.63 & 84 & 50 & (60) & 18 & (21) & 16 & (19) & Sensor Medics S4049 \\
\hline 33 & 191 & Portland & USA & 34 & 1.64 & 175 & 108 & (62) & 41 & (23) & 26 & (15) & Spirotech S500 \\
\hline 34 & 220 & Melbourne & AUS & 34 & 1.63 & 230 & 125 & (54) & 51 & (22) & 54 & (24) & Hewlett Packard \\
\hline
\end{tabular}

Centres are displayed in the same order as in figures 1-4. Code: European Community Respiratory Health Survey Code; B: Belgium; D: Germany; E: Spain; F: France; IR: Ireland; I: Italy; NL: The Netherlands; UK: United Kingdom; IC: Iceland; N: Norway; S: Sweden; NZ: New Zealand; USA: United States of America; AUS: Australia. 
et al. [10] underpredicted FVC and FEV1, and why the FEV1/FVC ratio is underpredicted by PAoLETTI et al. [4] was, however, beyond the scope of this study. Table 4 suggests that an even more marked underprediction of FVC and FEV 1 by both ECSC [1, 7] and KNuDson et al. [10] should be expected if the study had been constrained to the ECRHS subjects, i.e. lifetime nonsmokers who were highly screened for health status.

The standardized prediction deviation for a given prediction equation is a dimensionless index that indicates how far the mean observed lung function value for FVC (or FEV1) in the ECRHS is removed from the predicted value. Since the calculation of the standardized prediction deviation involves a correction by the RSD of the corresponding prediction equation, this index seems adequate to evaluate the impact of the use of a given set of prediction equations in the clinical setting. The analysis of the standardized prediction deviations agrees with the message given in the Results section, except for predicted FEV1 by PAOLETTI et al. [4] in females, which showed the highest underestimation among the five reference equations.

It must be emphasized that the present study was not undertaken to propose new common standards, but only to examine the mean prediction deviations of the five sets of prediction equations (table 2). The study shows that the use of the European Coal and Steel Community (ECSC) equations $[2,7]$ in the age interval analysed may provoke significant underestimation of spirometric results and it prompts the need for a re-evaluation of the current European recommendations on lung function reference values [7].

\footnotetext{
Acknowledgements: The co-ordination of this work was supported by the European Commission and we are grateful to the late C. Baya and M. Hallen for their help during the study and to K. Vuylsteek and the members of the COMAC for their support.
}

The following grants helped to fund the local studies. Australia: Allen and Hanbury's; Belgium: Belgian Science Policy Office, National Fund for Scientific Research; France: Ministère de la Santé, Glaxo France, Institut Pneumologique d'Aquitaine, Contrat de Plan Etat-Région Languedoc-Roussillon, CNMATS, CNMRT (90MR/10, 91AF/6), Ministre delégué de la santé, RNSP; Germany: GSF, and the Bundesminister für Forschung und Technologie, Bonn; Greece: The Greek Secretary General of Research and Technology, Fisons, Astra and Boehringerlngelheim; India: Bombay Hospital Trust; Italy: Ministerio dell'Università e della Ricerca Scientifica e Tecnologia, CNR, Regione Veneto grant RSF No.381/05.93; New Zealand: Asthma Foundation of New Zealand, Lotteries Grant Board, Health Research Council of New Zealand; Norway: Norwegian Research Council project No. 101422/310; Portugal: Glaxo Farmacêutica Lda, Sandoz Portugesa; Spain: Ministerio de Sanidad y Consumo FIS grants No.91/0016060/00E-05E, 92/ 6975, 95/0975, and grants from Hospital General de Albacete, Hospital General Juan Ramón Jiménez, Consejeria de Sanidad Principado de Asturias; Sweden: the Swedish Medical Research Council, the Swedish Heart Lung Foundation, the Swedish Association against Asthma and Allergy; Switzerland: Swiss National Science Foundation grant 4026-28099; UK: National Asthma Campaign, British Lung Foundation, Dept of Health, South Thames Regional Health Authority; USA: US Dept of Health, Education and Welfare Public Health Service Grant No.2 s07 RR05521-28.

\section{List of principal participants}

Co-ordinating Centre (London): P. Burney, S. Chinn, C. Luczynska, D. Jarvis, E. Lai.
Project Management Group: P. Burney (Project Leader), S. Chinn, C. Luczynska, D. Jarvis, P. Vermeire (Antwerp), H. Kesteloot (Leuven), J. Bousquet (Montpellier), D. Nowak (Hamburg), J. Prichard (Dublin), R. de Marco (Verona), B. Ricken (Groningen), J.M. Antó (Barcelona), J. Alves (Oporto), G. Boman (Uppsala), N. Nielsen (Copenhagen), P. Paoletti (Pisa).

Participating Centres: Austria: W. Poop (Vienna); Australia: M. Abramson, J. Kutin (Melbourne); Belgium: P. Vermeire, F. van Bastelaer (Antwerp South, Antwerp Central); France: J. Bousquet, J. Knani (Montpellier), F. Neukirch, R. Liard (Paris), I. Pin, C. Pison (Grenoble), A. Taytard (Bordeaux); Germany: H. Magnussen, D. Nowak (Hamburg); H.E. Wichmann, J. Heinrich (Erfurt); Greece: N. Papageorgiou, P. Avarlis, M. Gaga, C. Marossis (Athens); Iceland: T. Gislason, D. Gislason (Reykjavik); Ireland: J. Prichard, S. Allwright, D. MacLeod (Dublin); Italy: M. Bugiani, C. Bucca, C. Romano (Turin), R. de Marco Lo Cascio, C. Campello (Verona); A. Marinoni, I. Cerveri, L. Casali (Pavia); The Netherlands: B. Rijcken, A. Kremer (Groningen, Bergen-op-Zoom, Geleen); New Zealand: J. Crane, S. Lewis (Wellington, Christchurch, Hawkes Bay); Norway: A. Gulsvik, E. Omenaas (Bergen); Portugal: J.A. Marques, J. Alves (Oporto); Spain: J.M. Antó, J. Castellsagué, J. Sunyer, J. Soriano, J. Roca, F. Burgos, A. Tobías (Barcelona); N. Muniozguren (Bilbao), J. Ramos Gonzalez, A. Capelastegui (Galdakao), J. Castillo, J. Rodríguez-Portal (Seville), J. Martínez-Moratalla, E. Almar (Albacete), J.A. Maldonado Pérez, A. Pereira, J. Sánchez (Huelva), J. Quirós, I. Huerta, F. Payo (Oviedo); Sweden: G. Boman, C. Janson, E. Björnsson (Uppsala), L. Rosenhall, E. Norrman, B. Lundbäck (Umeå), N. Lindholm, P. Plaschke (Göteborg); Switzerland: U. Ackermann-Liebrich, N. Künzli, A. Perruchoud (Basel); UK: M. Burr, J. Layzell (Caerphilly), R. Hall (Ipswich), B. Harrison (Norwich), J. Stark (Cambridge); USA: S. Buist, W. Vollmer, M. Osborne (Portland).

\section{References}

1. American Thoracic Society. Lung function testing: selection of reference values and interpretative strategies. Am Rev Respir Dis 1991; 144: 1202-1218.

2. Quanjer PH. Standardized lung function testing. Bull Eur Physiopathol Respir 1983; 19: 66-92.

3. Roca J, Sanchis J, Agustí-Vidal A, et al. Spirometric reference values for a mediterranean population. Bull Eur Physiopathol Respir 1986; 22: 217-224.

4. Paoletti P, Pistelli G, Fazzi P, et al. Reference values for vital capacity and flow-volume curves from a general population study. Bull Eur Physiopathol Respir 1986; 22: 451-459.

5. Morris J, Koski A, Johnsons LC. Spirometric standards for healthy nonsmoking adults. Am Rev Respir Dis 1971; 103: 57-67.

6. Miller A, Thornton JC, Warshaw R, Bernstein J, Selikoff IJ, Teirstein AS. Mean and instantaneous expiratory flows, FVC and FEV1: prediction equations from a probability sample of Michigan, a large industrial state. Bull Eur Physiopathol Respir 1986; 22: 589-597.

7. Quanjer PH, Tammeling GJ, Cotes JE, Pedersen OF, Peslin R, Yernault JC. Lung volumes and forced ventilatory flows. Report working party: Standardization of lung function testing. Eur Respir J 1993; 6: 5-40.

8. Verhey NE, Ross CM, Wassili R, Jansen HM. Evaluation of reference values for maximal expiratory flow-volume curves in elderly people (Abstract). Eur Respir J 1992; 5: 409s.

9. Castellsagué J, Burgos F, Sunyer J, Barberà JA, Roca J, for the Barcelona Collaborative Group on Reference Values for Pulmonary Function Testing and The Spanish Group of The European Community Respiratory Health Survey. Prediction equations for forced spirometry from European origin population. Respir Med 1998; 92: 401407.

10. Knudson RJ, Lebowitz MD, Holdberg CJ, Burrows B. 
Changes in normal maximal expiratory flow-volume curve with growth and aging. Am Rev Respir Dis 1983; 127: 725-734.

11. Crapo RO, Morris AH, Gardner RM. Reference spirometric values using techniques and equipment that meet ATS recommendations. Am Rev Respir Dis 1981; 123: 659664.

12. ATS Statement. Snowbird workshop on standardization of spirometry. Am Rev Respir Dis 1979; 119: 831-837.

13. Burney PGJ, Luczynska P, Chinn S, Jarvis D. The European Community Respiratory Health Survey. Eur Respir J 1994; 7: 954-960.

14. United Medical and Dental Schools of Guy's and St.Thomas's Hospitals, London. Protocol for The European Community Respiratory Health Survey, 1993.

15. European Community Respiratory Health Survey. Varia- tions in the prevalence of respiratory symptoms, selfreported asthma attacks, and use of asthma medication in the European Community Respiratory Health. Eur Respir J 1996; 9: 687-695.

16. Pistelli G, Carmignani G, Paoletti P, et al. Comparison of algorithms for determining the end point of forced vital capacity maneuver. Chest 1987; 91: 100-105.

17. American Thoracic Society. Standardization of spirometry: 1994 update. Am J Respir Crit Care Med 1995; 152: 1107-1136.

18. Weiss ST, Ware JH. Overview of issues in the longitudinal analysis of respiratory data. Am J Respir Crit Care Med 1996; 154: S208-S211.

19. Ware JH, Weiss ST. Statistical issues in longitudinal research on respiratory health. Am J Respir Crit Care Med 1996; 154: S212-S216. 